\title{
Una cabeza romana en mármol atribuible al Llano de la Consolación (Montealegre del Castillo, Albacete)
}

\author{
MONICA RUIZ BREMÓN
}

El Llano de la Consolación (Montealegre del Castillo, Albacete), ha sido durante muchos años, y puede seguir siéndolo si su suerte no cambia, cantera inagotable de sorpresas en la arqueología del sudeste peninsular. A través de estas lineas me propongo una llamada de atención acerca de lo mucho que podrían aportar nuevos trabajos arqueológicos en el yacimiento, sumándome asi a la práctica totalidad de los autores que, desde una u otra perspectiva, han rozado el tema y han concluido en el mismo sentido.

$Y$ es que a este yacimiento se le han ido atribuyendo, al paso del tiempo, las más dispares calificaciones. En muchos casos éstas han sido fruto de elucubraciones teóricas; en otros, descubrimientos parciales que la necesidad hacia elevar a nivel de categoria.

Buena parte del problema fue expuesto por A. Fernández de Avilés en un trabajo publicado en $1953^{\prime}$. En él desbrozaba, con su minuciosidad característica, el largo camino recorrido por las “investigaciones» en el Llano de la Consolación desde 1891 hasta el momento. Se refería el autor a lo que con más propiedad podriamos denominar las "rebuscas" sobre el lugar, al menos hasta 1914, fecha del inicio de los trabajos de J. Zuazo. La etapa que sigue a ésta concluye con las primeras y únicas excavaciones cientificas en el yacimiento, obra de J. Sánchez Jiménez y del propio Fernández de Avilés ${ }^{2}$, así como con la redacción del citado artículo.

"Excavaciones en el Llano de la Consolación (1891-1946)", APL, 4, 1953, 195-209.

2 SANChez Jimenez, J., "Excavaciones y trabajos arqueológicos en la provincia de Albacete de 1942 a 1946", Informes y Memorias, 15, 1947, 31-44; “Llano de la Consolación (Albacete). La Torrecilla (Campaña de 1947)", NAH, I, 1952, 92-6; "Labor de la Comisaria Provincial de Excavaciones Arqueológicas de Albacete", II C.A.N. (Madrid 1951), Zaragoza 1952, 381-6. 
A la hora de realizar este trabajo, dedicado a la presentación de un ejemplar escultórico atribuido al Llano de la Consolación, me ha parecido de interés añadir a la ya clásica revisión de Fernández de Avilés, no sólo los planteamientos teóricos que incidieron en la elección del lugar para llevar a cabo aquéllas "rebuscas" y excavaciones, sino también las tendencias interpretativas que han visto la luz desde aquel momento. Adelantando en parte los resultados de esta investigación sobre el papel, diré que, curiosamente, todos aquéllos que dejaron por escrito memoria de sus trabajos, nos dicen "qué" buscaban y "qué no" encontraron. $Y$ esto, evidentemente, ha marcado la historia de la investigación sobre el Llano. En unos casos, sencillamente, porque se abandonó la búsqueda; en otros, porque sólo se "leyó», entre lo hallado, lo que podia acomodarse a lo buscado.

Tratando de no reiterar lo dicho por Fernández de Avilés, e incluyendo algunos datos no recogidos por él, me limitaré pues a indicar cuáles son, en mi opinión, los principales hitos de este proceso:

La primera referencia historiográfica al yacimiento del Llano de la Consolación se encuentra en Bastetania y Contestania del Reyno de Murcia, del Canónigo Juan Lozano, esto es, en 1794, al identificarse el lugar con la antigua ciudad de Ello, sede de un Arzobispado hasta su destrucción en 921 por las tropas de Rodrigo II de León ${ }^{3}$. La segunda la hallamos en el Sumario de las Antigüedades romanas que hay en España de J. A. Ceán Bermúdez (Madrid 1832), en donde se hace referencia a las "ruinas romanas" próximas a la ermita de Nuestra Señora de la Consolación ${ }^{4}$.

Tras la obra de Ceán Bermúdez en 1830 se ha de hacer un inciso, para tratar de una interpolación en la tradición historiográfica del Llano de la Consolación, que supuso la atribución sistemática a un autor de una determinada teoría. La cosa no revestiria mayor interés sino fuera porque la teoria de identificar Llano y Ello, por lo demás nada novedosa, como hemos visto, se atribuiria en algún momento a A. Fernández Guerra, autor estrechamente ligado a la investigación del Cerro de los Santos por un trabajo concreto: la Contestación al Discurso de Ingreso de Juan de Dios de la Rada y Delgado en la Real Academia de la Historia (Madrid 1875).

En su Contestación, Fernández Guerra sitúa la "acrópolis» de Ello, un «hemeroskopeion» focense, en el Monte Arabi. El Cerro de los Santos se$11-19$

Cfr., Serrano, P., “La Plaine de la Consolation et la Ville Ibèrique d'Ello", BH, I, 1899,

4 Op. cit., pág. 94. 
ria un "barrio" de dicha ciudad denominado Pale ${ }^{5}$. en ningún momento, sin embargo, se liga en su estudio El Llano de la Consolación con Ello.

Tal atribución - no sabemos a quién debida exactamente, aunque ya aparece reflejada en un trabajo de A. García y Bellido ${ }^{6}$ - consagró, en la historiografia moderna, una relación entre el Cerro de los Santos y el Llano de la Consolación ya plenamente admitida, de facto, desde finales del siglo pasado y por otras causas. $Y$ esta vinculación temprana de uno y otro yacimiento iba a resultar, a la larga, el principal escollo a la hora de su estudio y correcta interpretación histórica y arqueológica. No es el

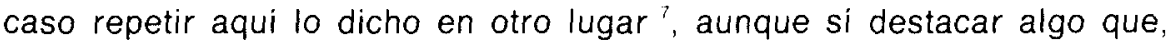
en su dia, resultó evidente tanto para mi misma como para otros muchos a la hora de estudiar el santuario del Cerro de los Santos. $Y$ es que, metafóricamente hablando, habia que "pasar" por el Llano para "llegar» al Cerro. Este hecho, lo vamos a ver a continuación, paralizó, cuando no deformó irremisiblemente a veces, el conocimiento del Llano de la Consolación.

De nuevo aparece el Llano de la Consolación en la escena «historiográfica" y por primera vez en la investigación "arqueológica" entre 1891 y $1898^{8}$ por obra de dos aficionados locales, Pascual Serrano, maestro de Bonete, y José Antonio González, cura de Montealegre. Los resultados de los trabajos de Serrano se publican en 1899, permitiendo al autor deducir, por el carácter de sus hallazgos, que bajo el yacimiento del Llano se encontraba asentada una ciudad, la de Ello. Asi lo confirmaban, a su entender, los hallazgos de monedas, los muros de hormigón romano y los restos de una calzada romana -identificada por A. J. González con la Vía Augustea- próxima a la ermita de Nuestra Señora de la Consolación. La evidencia hablaba por sí sola y José Antonio González pudo cumplir su deseo de autodenominarse "cura de Ello" ${ }^{9}$. En cuanto a su adscripción cultural, las urnas cinerarias, los restos metálicos y, especialmente, los numerosos fragmentos de escultura similares a los del $\mathrm{Ce}$ -

Op. cit., págs. 123 y ss

"La Dama de Elche y el conjunto de piezas arqueológicas reingresadas en España en 1941. Madrid 1943, pág. 167.

7 Vid., Ruiz Bremón, M., Los exvotos del Santuario ibérico del Cerro de los Santos. Albacete 1989, págs. 32-52, para la historia de la investigación sobre este yacimiento.

${ }^{*}$ El Padre Escolapio de Yecla Lasalde también nos da una breve referencia al Llano (para el "Cerro" de la Consolación en su articulo "Las Antigüedades de Yecla", La Ciencia Cristiana, XVI, 1880, pág. 470). Se refiere en concreto al hallazgo en él de piedras labradas y de vasos de cerámica de estilo «egipcio». Su implicita relación con las obras procedentes del Cerro de los Santos debió de influir en la bibliografia posterior, habida cuenta de que éste fue uno de los primeros estudiosos del yacimiento en cuestión

"Fernandez de Avilés, A. Op. cit., en nota 1, pág. 199. 
rro de los Santos, permitian conceptuar a tal ciudad de «ibérica», a pesar de que por entonces aún estuviera poco clarificado este último adjetivo.

Las esculturas encontradas por los dos eruditos locales pasarian, en buena parte, a manos de Arthur Engel, comisionado del Museo del Louvre por aquellas fechas e investigador muy ligado a la futura "lectura" del Llano de la Consolación.

En efecto, ya en 1892, A. Engel iba a provocar un giro de noventa grados en la interpretación del yacimiento del Llano. Aquéllo que, como hemos visto, quizás estuviera ya en las conciencias pero aún no habia sido fijado por escrito, esto es, la hermanación del Llano de la Consolación con el Cerro de los Santos, fue una teoria salida de la pluma de Engel en el momento en que éste afirmó que en el Llano hubo un santuario «de la misma época que el del Cerro" ${ }^{10}$. Lo hallado por él en los lugares ya explorados por Serrano y González del "Campo de Blas» y en el de "San Antón»-por cierto que en una vertiginosa campaña «de media jornada»- tales como fragmentos de escultura y urnas cinerarias, así como lo comprado a Pascual Serrano para el Louvre, apuntaban en esta dirección. Engel no dio mayor importancia a los restos de habitación, en particular romanos, que sin duda aflorarian todavía en la zona próxima a la ermita, igualmente explorada por González y tan sólo cita de pasada un «capitel corintio" abandonado sobre la carretera de Montealegre.

Pierre Paris, que en 1905 también se interesa por el yacimiento, hace que aumente la ambigüedad interpretativa del Llano de la Consolación al no clasificar los hallazgos escultóricos del mismo como atribuibles a una ciudad o a un santuario, pero sí afirmar que son «idénticos en arte e industria a los del Cerro" ". Si se hace eco, en cambio, de la cita de Ceán Bermúdez acerca de las “ruinas romanas" existentes en él. Ahora bien, en 1910 parece pronunciarse por la identificación del Llano con la ciudad ibérica de Ello y a sus habitantes con los fieles peregrinos del Cerro de los Santos, al imaginárselos “marchant vers le temple proche» del mismo ${ }^{12}$.

Así las cosas, en 1912 Julián Zuazo Palacios, otro erudito local ligado tanto a la investigación de uno como de otro yacimiento, comienza su exploración en la zona, aunque sólo de 1914 en adelante con los perti-

\footnotetext{
10 "Rapport sur une mission archéologique en Espagne (1891)", Nouvelles Archives des Missions Scientifiques et Littéraires, III, 1892, pág. 193.

1 Essai sur l'art et l'industrie de l'Espagne primitive. Paris 1903, pág. 258.

12 "Promenades Archéologiques en Espagne», BH, X, 1908, págs. 56 y 58, respectivamente.
} 
nentes permisos ${ }^{13}$. Con él, por cambiar los lugares de búsqueda, cambia también la tónica de los hallazgos en el Llano de la Consolación.

Asi, de sus publicaciones se deduce que Zuazo excavó en una zona de necrópolis de época romana, al sur de la carretera local de Montealegre que atraviesa el Llano. Así lo delatan sus hallazgos de tumbas de incineración acompañadas de campaniense y sigillata, de una estela de piedra con epigrafe latino ${ }^{14}$, restos de sillares y "abundantísimo" hormigón romano y monedas imperiales. Atendiendo a lo publicado por él, en el lugar conocido como "haza de pascual Campos» habria hallado tambièn "cimientos de casas romanas". Zuazo, como otros con anterioridad, buscaba en el Llano la ubicación de la ciudad de Ello y en lugar de un núcleo de habitación claro halló testimonios tanto de necrópolis de incineración como de inhumación — sin adscribir cultural o cronológicamente por su parte-, escultura similar a la del Cerro de los Santos, y, en suma, restos de varias cronologías y carácter ${ }^{15}$. Como vemos, la interpretación global del yacimiento se estaba convirtiendo en una ardua tarea, a cuyo esclarecimiento, por fortuna, iban a contribuir en parte los esfuerzos de J. Sánchez Jiménez.

En efecto, la historia de las excavaciones cientificas en el Llano de la Consolación comienza y termina entre 1946 y 1947 con los trabajos ya citados de Joaquin Sánchez Jiménez. El objetivo de estos trabajos de campo en el Llano se cifraba en la localización del poblado ibérico - «uera o no Ello", según frase de su excavador ${ }^{16}$ - al que atribuir las tumbas de incineración con restos escultóricos hallados hasta entonces. Dada la gran amplitud de la zona - aspecto éste que hasta la fecha no habia sido tenido en cuenta a la hora de interpretar globalmente el yacimiento--, se acometieron diversos trabajos en puntos determinados, algunos ya explorados, otros nuevos ${ }^{17}$. Entre los primeros y en concreto en el lugar donde en su dia Zuazo dijera haber hallado restos de casas romanas, esto es, en el haza de Pascual Campos, fueron hallados restos de tejas, hormigón

13 Fernandez de Avilés. A., Op. cit, en nota 1, pág. 204, nota 30.

${ }_{14}$ Zuazo la transcribe de la siguiente manera: CEMIN/ / I.CILO.H.AH. (Trabajos Arqueológicos en Montealegre del Castillo, Albacete). Sevilla, Asociación Española para el Progreso de las Ciencias, 1917, pág. 24.

15 Ibidem, págs 21-32; Meca. Contribución al estudio de las ciudades ibéricias. Madrid 1916, págs. 41-8.

${ }^{16}$ Op. cit, en nota 2 (1947), pág. 34.

" La búsqueda se desarrolló en los campos pertenecientes a Pascual Campos, Emilio y Eloy Sánchez, José y Juan Tornero, Martin Silvestre, Pedro Sánchez, Blas y Juan de Marisparza ("La Torrecilla»). Fue infructuosa en el caso de los campos de José y Juan Tornero y en el que se creyó era «el famoso" de Blas, más tarde identificado con la propiedad del Sr. Dabasa (Op. cit, en nota 1, pág. 207, nota 207). 
y sillares de piedra, terra sigillatta, vidrio, etc. Igualmente, en el haza de Eloy Sánchez, de Emilio Sánchez y de Martín Silvestre se pudieron recoger fragmentos de molino, cerámica y mortero romanos e incluso, en la primera, «teselas y restos de mosaico" ${ }^{18}$. Entre los lugares de nueva exploración se hallaba, por su parte, el de la "Torrecilla" (0 "Torrecica", en otros casos), en el que se excavó una necrópolis de época ibérica alta con un importante monumento funerario decorado con escultura y con un ajuar de mayor antigüedad que lo encontrado en otros puntos, siendo digna de reseñar la presencia de vasos griegos de figuras rojas y ausencia total de sigillatta ${ }^{19}$.

Llegados a este punto creo que es de sumo interés destacar un hecho sobre el que llamaría la atención años más tarde M. C. Marín Ceballos en un artículo que hizo época ${ }^{20}$ : en un primer momento J. Sánchez Jiménez parecía inclinado a considerar lo hallado en "La Torrecilla" como perteneciente a un monumento funerario, modificando su interpretación algo después. En efecto, en 1947 este autor denomina lo hallado «túmulo" -aunque añade: «no sabemos si con propiedad»-, comparándolo con "dos recuadros o cuadriláteros semejantes" procedentes de las necrópolis ibéricas de Hoya de Santa Ana y Casa del Monte ${ }^{21}$. En definitiva, una "construcción" excepcional que duda en calificar como "templo" o "sepulcro". No sabemos, sin embargo, qué es lo que movió a Sánchez Jiménez a modificar su interpretación años más tarde, en $1952^{22}$. En este momento cobró forma su teoria de que el Llano de la Consolación «funcionó" en origen como un Santuario del estilo del Cerro de los Santos, hasta que más tarde se convirtió en necrópolis. Según Marin Ceballos, la lectura de lo hallado en "La Torrecilla» como procedente de un Santuario similar al del Cerro, en la tónica de la historiografia antigua desde los tiempos de Engel y en contradicción con sus paralelos en otras necrópolis conocidas por el propio Sánchez Jiménez, sólo pudo deberse al uespejismo del santuario del Cerro" ${ }^{23}$.

La frase es sin duda acertada, como todo el trabajo que, sobre el particular, debemos a su autora y que finalmente acabaria por «desmontar»

18 Op. cit., en nota 2 (1947), pág. 37.

19 Fernández de Avilés, A., Op. cit., en nota 1, pág. 208

20 "El supuesto "santuario" iberico del Llano de la Consolación (Montealegre del CastiHo, Albacete)", Habis, 10-11, 1979-80, págs. 233 y ss.

${ }^{21}$ Op. cit., en nota 2 (1947), págs. 42-3

22 Op. cit, en nota $2(1952$, b).

${ }^{\prime 3}$ Op. cit, en nota 20 , pág. 238 
la estéril teoría del "Santuario del Llano» ${ }^{24}$ y a consagrar el carácter de necrópolis de lo excavado en aquel punto concreto por Sánchez Jiménez. En este caso, como en otros, no por la vía de los trabajos de campo sino de la revisión de la historiografia, antigua o más reciente, a la luz de los avances en la investigación arqueológica. Bien es verdad que de nuevo se dejaban por analizar otras evidencias arqueológicas, de otro carácter y de otra cronologia, igualmente proporcionadas por el Llano de la Consolación.

En la misma linea se insertan los más modernos estudios que han tratado directa o indirectamente sobre el yacimiento en cuestión: acopio de datos, revisión de la bibliografía, relación del yacimiento con otros en virtud de su proximidad o tipo de hallazgos y estudio de objetos atribuidos al Llano pero sin contexto arqueológico ${ }^{25}$.

Así, con anterioridad al trabajo de Marin Ceballos, es de destacar, por el enorme peso que tuvieron sus escritos en el área de la investigación ibérica, el debido a A. García y Bellido, en la línea de Serrano y que, a su vez, influyó en G. Nicolini ${ }^{26}$. Para Garcia y Bellido, los «restos de una ciudad visibles en el Llano" serian identificables con la ciudad de Ello ${ }^{27}$.

Otro carácter tiene, y presenta mayores novedades, el dedicado por $P$. Sillières al trazado de la Via Heraklea, también conocida como "Camino de Anibal", ya que en él se hacen algunas referencias al Llano de la Consolación. Así, la ciudad situada al pie del "Camino" a su paso por el Llano es identificada por el autor del mismo con la romana Egelasta que citan Plinio y Estrabón, y no con Ello ${ }^{28}$. La razón final por la que el

${ }^{24}$ Todavia se encuentra reflejada ésta, sin embargo, en el trabajo de LuCAS, M. R., "Santuarios y dioses en la Baja época ibérica", La Baja Época lbérica (Actas de la Mesa Redonda celebrada en conmemoración del $X$ aniversario de la Asociación Española de Amigos de la Arqueologia). Madrid 1981, págs. 233-93.

${ }_{25}$ Por ejemplo, el dedicado por J. Sánchez Jiménez a una «Tetradracma del Llano de la Consolación (Albacete)", Crónica del IV Congreso Arqueológico del Sudeste. Elche, 1948. Cartagena, 1949, 261-6. Y el de A. Garcia y Bellido a un Satyros ictyphalicos, hoy en el Museo Arqueológico Nacional, procedente de una venta de P. Serrano al Museo del Louvre (Hispania Graeca. Madrid 1948, II, 91-3, lám. XXVI).

${ }^{26}$ Nicolini, G., "A propos de l'archaïsme lbèrique: les trois têtes du Llano de la Consolation au Musée du Louvre". Homenaje a Garcia y Bellido. Ill. Revista de la Universidad Complutense, XXVI, 109, 1977, pág. 27, nota 6. En este articulo Nicolini se limita a recoger noticias anteriores acerca de Ello y su identificación con el Llano de la Consolación, sin pronunciarse sobre el particular. Estas noticias han sido tomadas de García y Bellido (Vid. Infra) y repiten algunos de sus errores.

2' Op. cit., en nota 6, pág. 167 ( $\mathrm{n} .^{\circ} 157$, como indica G. Nicolini en nota 26).

${ }^{28}$ " "Le Camino de Anibal". Itineraire des gobelets de Vicarello, de Castulo à Saetabis", MCV, 13, 1977, págs. 31-83. En efecto, para el autor, en el Llano confluyen varias razones para tal identificación: proximidad de minas de sal, restos de una ciudad y coincidencia con 
autor defiende esta identificación tiene mucho que ver con la presencia de depósitos de sal cercanos, tal y como afirmaba Plinio refiriéndose a Egelasta ${ }^{29}$.

Finalmente, otros trabajos se han dedicado recientemente al estudio del Llano de la Consolación en su aspecto de necrópolis ibérica ${ }^{30}$, aspecto, por lo demás, no reñido con la posible localización en él de una ciudad romana, quizás Egelasta, siguiendo en esto a P. Sillières ${ }^{31}$.

Ahora bien, resulta harto evidente que el estudio del Llano de la Consolación está, hoy por hoy, muy lejos de darse por concluido. Recapitulando lo dicho en estas lineas, hemos visto cómo, desde los tiempos del Canónigo Lozano hasta nuestros dias, el Llano ha sido considerado una ciudad romana, un santuario prerromano, y, alternativamente, una ciudad y una necrópolis ibérica por la que, además, pasaba un antiguo camino ibérico convertido con posterioridad en via romana. $Y$ es que, en efecto, hay indicios suficientes para pensar que en el Llano de la Consolación podriamos tener ante nosotros tanto un poblado ibérico cuyas últimas fases alcanzaran la plena romanidad, como una villa altoimperial relacionada con la Via Heraklea ${ }^{32}$, y hasta una ciudad romana de nombre Egelasta... Todo ello, con sus correspondientes zonas de necrópolis y sin hacer alusión a otros testimonios de ocupación posterior del lugar, en concreto árabe ${ }^{33}$. Por ello, dada la amplitud del lugar y el tono variado de los hallazgos, y en espera de lo que aporten futuras excavaciones en él, lo prudente sería empezar a hablar del Llano en clave de yuxtaposición y no, como se ha venido haciendo hasta ahora, de disyunción.

Estas son las razones que me mueven a participar en el reestudio del Llano de la Consolación mediante la presentación de un testimonio es-

\footnotetext{
el itinerario descrito en los Vasos de Vicarello (pág. 81). A. Blanco, aludiendo a argumentos de tipo lingüistico, se inclinó sin embargo por identificar Yecla con la Egelasta de las fuentes y la igalosken de las monedas ibéricas (Historia del Arte Hispánico I. La Antigüedad II. Madrid 1981, pág. 29). Por mi parte, recogi esta idea en 1989 (Op. cit. en nota 7, págs. 1901), que hoy creo exigiria una comprobación.

${ }^{29}$ Estrabón, II, 4-9; Plinio, NH, XXXI, 80.

${ }^{30}$ Ruano, E., "Materiales escultóricos ibéricos procedentes del Llano de la Consolación (Montealegre del Castillo, Albacete): estado de la cuestión», BSEAA, 29, 1990, págs. 37-47. Blanouez, J., La formación del mundo ibérico en el sureste de la Meseta (Estudio arqueológico de las necrópolis ibéricas de la provincia de Albacete). Albacete 1990, págs. 351-3; 375-6.

${ }^{31}$ Blanouez, J., Op. cit., en nota 30 , pág. 52, nota 77.

37 No debe ser confundida con la villa localizada recientemente por Francisco Brotons en término de Yecla, en un lugar denominado "Viña de Marisparza" (Yakka. Revista de Estudios Yeclanos, 1, diciembre de 1989, págs. 127-8).

${ }^{3}$ Fernandez de Avilés, A., Op. cit., en nota 1, pág. 13.
} 
Una cabeza romana en mármol atribuible al Llano de la Consolación ...
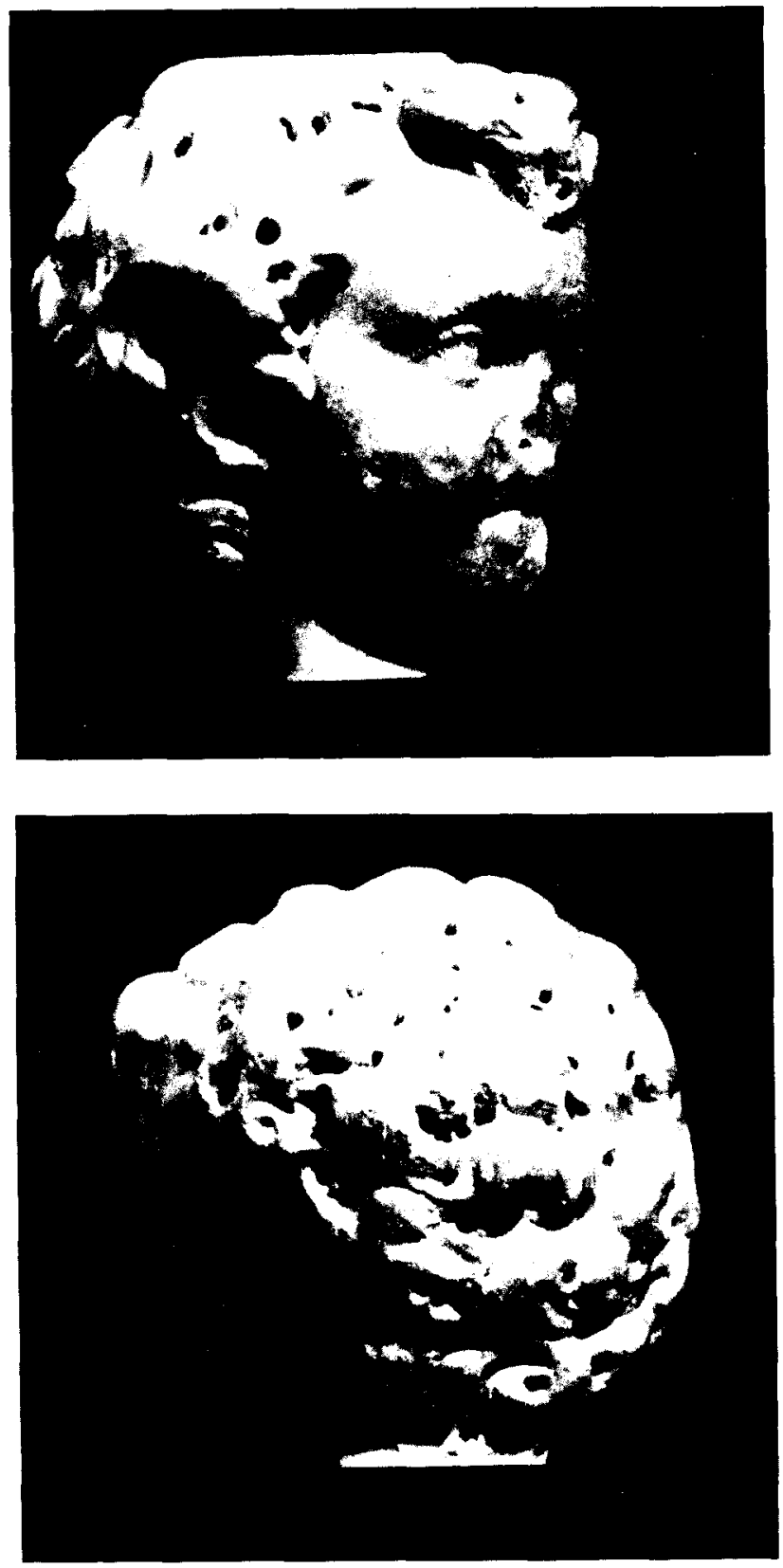
cultórico inédito ligado al yacimiento. Hace ya algún tiempo tuve noticia de esta cabeza romana en mármol, si bien su estudio quedó pospuesto por diversos motivos. La renovada ola de interés por el Llano, sumada a mi nada reciente curiosidad por este yacimiento, me han llevado a dar hoy pública noticia de ella.

Perteneciente en su momento a Julián Zuazo Palacios, se trata hoy por hoy de una pieza objeto de coleccionismo de la cual se ignoran datos ciertos sobre procedencia y circunstancias del hallazgo. Sin embargo, la tradición familiar la ha relacionado siempre con el yacimiento del Llano, transmitiendo con ello probablemente la información que el propio Zuazo proporcionara. Las suficientes garantias que, aún no siendo un profesional, ofrece la figura de Zuazo ${ }^{34} \mathrm{y}$ las caracteristicas que concurren en el citado yacimiento y que ya han sido expuestas, me han llevado a no dudar, en principio, de tal atribución.

No ha de olvidarse que Zuazo realizó, por su cuenta y con anterioridad a la excavación de Sánchez Jiménez, diversas campañas tanto en el Llano como en el Cerro, fruto de las cuales son materiales de toda indole conservados en diversas colecciones, privadas y oficiales. Es pues factible que la pieza que motiva este estudio y que, según tradición, se conservaba "desde siempre" en el despacho particular de este aficionado a la Arqueologia, fuera un hallazgo fortuito anterior o muy posterior a los que él mismo dio a conocer a través de diversas publicaciones ${ }^{35}$.

Se trata de una efigie infantil realizada en mármol blanco, con unas dimensiones totales de $19,5 \mathrm{~cm}$ de altura, 17 de ancho y 17,5 de profundidad (figs. 1-2).

Su estado de conservación, si excluimos el volumen de la nariz, totalmente perdido, es relativamente bueno. La boca, la barbilla y el ojo izquierdo, también han sufrido pérdidas. En cuanto al cabello, su relieve se ha desgastado fundamentalmente en la zona que rodea el rostro, por lo que la huella del trépano es visible por toda la superficie del mismo, alli donde hubo bucles. La piedra, de color blanco amarillento, ha sido limpiada modernamente. Cabe también destacar que la cabeza está sesgada en horizontal al nivel del arranque del cuello, en cuya base presenta dos orificios circulares, uno de ellos centrado y posiblemente moderno y con función sustentante.

\footnotetext{
${ }^{34}$ Bastante ilustrativo, en este sentido, es el trabajo de J. Sanchez Jiménez: “El IImo. Sr. don Julián Zuazo y Palacios", Boletin Arqueológico del Sudeste Español, 3, 1945, $280-4$.

${ }_{35}$ Además de las ya citadas (Vid. notas 14 y 15 ): «La villa de Montealegre y su Cerro de los Santos". Madrid 1916.
} 
Su rostro presenta los rasgos idealizados de un niño de corta edad, con el óvalo muy redondeado y carnoso. Los ojos, con indicación del párpado superior y sin señal de iris ni pupila, son pequeños y globulosos. La boca es breve y se halla ligeramente entreabierta. La nariz, perdida, ha dejado una huella triangular, en cuya base se observan también las de los orificios nasales, realizados mediante taladro.

Una melena abundante y ensortijada enmarca por completo el rostro del niño, cubriendo gran parte de las orejas y alcanzando finalmente la nuca. Sobre la frente, un abultado grupo de mechones forma un caracteristico tupé sobre la frente ${ }^{36}$.

Pese a su estado de conservación parcial y aunque carecemos de contexto arqueológico firme en el que sustentar una segura catalogación, es posible aventurar la datación de esta cabeza en virtud de su estilistica e iconografia. Así, la abundancia de bucles y su tratamiento voluminoso y despegado con respecto al cráneo parecen los caracteristicos de la estética de la segunda mitad del siglo $\| \mathrm{d}$. C., esto es, antoniana, si no algo posterior. Entre sus paralelos más próximos cabría citar los ejemplares de Tarragona ${ }^{37}$, Conimbriga ${ }^{38}$, Aquileia ${ }^{39}$, Side (Turquia) ${ }^{40}$ y el de procedencia desconocida del Museo de Sevilla, aunque fechado más tempranamente ${ }^{41}$. En la misma dirección apunta, ciertamente, el empleo exhaustivo del taladro para la realización de dichos bucles y para el tratamiento de los lacrimales, los orificios auriculares y los nasales.

Sobre su significado concreto seria aventurado ir más allá de su identificación con un Eros o un Dionysos niño, si es que no se trata de una simple efigie de niño ${ }^{42}$. De inclinarnos por la primera idea, hemos de figurarnos que su iconografia se complementaria probablemente con unas alas, una cornucopia, unas flores o frutos, una antorcha, etc., pues con toda probabilidad se trataria de una figura completa llegada hasta noso-

\footnotetext{
${ }^{36}$ Algunos paralelos de este elemento se encuentran en: POULSEN, V., Les portraits Romains. Copenhagen 1974 1I, n.. 16 (principe flavio) y 80 (Marco Aurelio niño); RICHTER, G.M.A., Romain Portrait. New York 1948, n. 74 (Antonino Pio); HeCkleR, A., Greek and Roman Portraits. New York 1972, PI. 229.

${ }^{3 i}$ Koppel, E. M., Die Römischen Skulpturen von Tarraco. Berlin 1985, n." 159, Tf. 71, 2-3. Alt: $0.22 \mathrm{~m}$.

${ }^{38}$ Corpus Signorum Imperii Romani. Portugal, Coimbra, 1990, n." 26, pág. 18. Alt: 0,16 m.

${ }^{39}$ Museo Archeologico di Aquileia. Catalogo delle Sculture Romane. Aquileia 1972, n." 158-160, pág. 54.

40 InAN, J., Roman Sculture in Side, 1975, n. 98 , Tf. 81, pág. 172. Alt: 0,18 m.

" Garcia y Bellido, A., "Museo Arqueológico de Sevilla. Catálogo de los Retratos Romanos". Madrid 1951, n. ${ }^{\circ}$ 14, pág. 17, fig. 14. 0,17 m.

${ }^{42}$ Reinach, S., Rèpertoire de la Statuaire Grecque et Romaine. Paris 1910. T. II, I, pág 125,$1 ; T$. II, II, págs. 427 y ss
} 
tros muy fragmentariamente. También cabe dentro de lo posible que hubiera formado parte de un grupo, siguiendo entonces la iconografia al uso entre los "erotes" romanos, de corte helenístico en cuanto al tema y ascendencia lisipea en cuanto a la forma ${ }^{43}$.

En cuanto a la razón de ser de esta pieza en un yacimiento hasta la fecha tenido por ibérico, baste recordar lo apuntado líneas más arriba. No sería éste, en modo alguno, el primer testimonio de carácter romano proporcionado por el Llano, antes lo contrario. Ya se ha hecho referencia a los restos de tumbas y de edificaciones en las que se pudieron constatar, en su momento, materiales de procedencia romana, con inclusión de tejas y teselas de mosaico, molinos, sillares labrados y otros elementos arquitectónicos, mortero, vidrio, monedas imperiales, campaniense y sigillata, etc. Podriamos pues estar ante una pieza de carácter decorativo procedente de una villa, rural o suburbana, o de un edificio de carácter urbano perteneciente al paso entre los siglos $\mathbf{~} \mid-1 i l d$ d. C. La actual revisión en el Museo de Albacete de los materiales procedentes de las campañas de Sánchez Jiménez, y la reanudación algún día de la exploración arqueológica del lugar, podrian, quizás, esclarecer esta hipótesis e ilustrarnos acerca de lo que fue "todo el ciclo vital del Llano" ${ }^{44}$.

${ }^{43}$ Bieber, M., The Sculpture of the Hellenistic Age. New York 1965, págs. 136 y ss.

${ }^{44}$ Fernandez de Avilés, A., Op. cit, en nota 1, pág. 209. 